\title{
Correction to: A new method to prevent seepage erosion of loess slope toe using the combination of filter pipe and siphon drainage
}

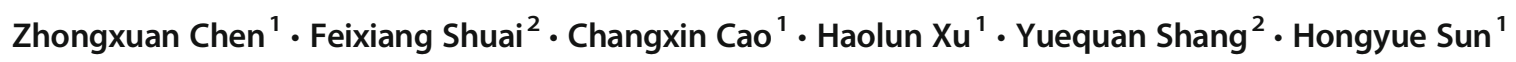

Published online: 17 March 2021

(C) Springer-Verlag GmbH Germany, part of Springer Nature 2021

Correction to: Bulletin of Engineering Geology and the Environment (2021) https://doi.org/10.1007/s10064-021-02182-w

Originally, the author's Acknowledgement was missing. The statement is presented here.

Acknowledgements The authors acknowledge the financial support of the National Key R\&D Program of China (Project no. 2018YFC1504704).

The Original article has been corrected.

The online version of the original article can be found at https://doi.org/ 10.1007/s10064-021-02182-w

\footnotetext{
Hongyue Sun

shy@zju.edu.cn

1 Ocean College, Zhejiang University, Zhoushan 316021, Zhejiang, China

2 College of Civil Engineering and Architecture, Zhejiang University, Hangzhou 310058, Zhejiang, China
} 